\title{
Análise do Potencial Turístico do Município de Rosário do Sul no Interior do Estado do Rio Grande do Sul
}

\author{
Análisis del Potencial Turístico del Municipio de Rosario del Sur en el \\ Interior del Estado de Rio Grande do Sul
Analysis of the Tourist Potential of the Municipality of Rosário do Sul in the State of Rio Grande do Sul

Janderlei Velasque Dal Osto ${ }^{1}$

Lucas Mauricio Willecker dos Santos ${ }^{2}$

Glenda Lima de Lima ${ }^{3}$

\begin{abstract}
Resumo
O termo turismo consiste em uma atividade econômica que está relacionada a viagens organizadas que, normalmente são realizadas a lazer. Porém as atividades turísticas podem ser de diferentes tipos (cultural, ecológico, econômico e afim). Nesse contexto, a pesquisa proporciona a motivação da realização do trabalho, que tem por finalidade explanar e analisar o potencial turístico de Rosário do Sul, caracterizando seus principais pontos turísticos e relacionar com a história do município, por isso, foram elencados não somente os pontos turísticos atuais do município, mas também, aqueles que já contribuíram conforme o resgate histórico de Rosário do Sul. Para a execução da pesquisa foi utilizada a amostra e coleta de imagens históricas e atuais com a finalidade de ilustrar melhor o ponto turístico de análise. Além disso, se fez o uso de levantamentos bibliográficos e documentais que nos auxiliaram durante toda a pesquisa para a realização do resgate histórico do município, essa etapa contou com a busca em acervos disponíveis em meio digital e acervo físico disponibilizado por escolas e pela prefeitura do município. Com os resultados a pesquisa apontou que o município possui um potencial turístico importante para a região central do estado, impulsionado pela atividade que exerce na função do Rio Santa Maria, que atrai pessoas dos demais municípios da região em função da Praia das Areias Brancas, bem como edificações antigas que denotam a cultura de diferentes imigrações presentes e com suas marcas registradas no patrimônio cultural do município.
\end{abstract}

Palavras-Chave: História; Pontos turísticos; Rosário do Sul; Turismo.

\section{Resumen}

El término turismo consiste en una actividad económica que está relacionada con viajes organizados que, normalmente se realizan por ocio. Pero las actividades turísticas pueden ser de diferentes tipos (cultural, ecológico, económico y afín). En este contexto, la investigación proporciona la motivación de la realización del trabajo, que tiene por finalidad explicar y analizar el potencial turístico de Rosário do Sul, caracterizando sus principales puntos turísticos y relacionarse con la historia del municipio, por lo que no se incluyeron no sólo los puntos que se ha convertido en una de las más importantes de la historia de la ciudad. Además, se hizo el uso de encuestas bibliográficas y documentales que nos ayudaron durante toda la investigación para la realización del rescate histórico del municipio, esa etapa contó con la búsqueda en acervos disponibles en medio digital y acervo físico disponibilizado por escuelas y por el ayuntamiento del municipio, municipio. Con los resultados la encuesta apuntó que el municipio posee un potencial turístico importante para la región central del estado, impulsado por la actividad que ejerce en la función del Río Santa María, que atrae personas de los demás municipios de la región en función de la Playa de las Arenas Blancas, como edificaciones antiguas que denotan la cultura de diferentes inmigraciones presentes y con sus marcas registradas en el patrimonio cultural del municipio.

\footnotetext{
${ }^{1}$ Mestrando do Programa de Pós-Graduação em Geografia da Universidade Federal de Santa Maria - PPGGEOUFSM; RS; Brasil; janderleijunior@gmail.com

${ }^{2}$ Licenciado em Geografia; Universidade Federal de Santa Maria - UFSM; RS; Brasil; lucasmauricio_sm@hotmail.com

${ }^{3}$ Mestranda em Letras; Universidade Federal de Pelotas - UFPel; RS; Brasil; glendalimadelima@ gmail.com
} 
Palabras claves: Historia; Puntos turisticos; Rosario do Sul; Turismo.

\begin{abstract}
The term tourism consists of an economic activity that is related to organized trips that are usually carried out at leisure. However the tourist activities can be of different types (cultural, ecological, economic and related). In this context, the research provides the motivation to carry out the work, which aims to explain and analyze the tourist potential of Rosário do Sul, characterizing its main tourist attractions and relate to the history of the municipality, so that not only the points but also those who have contributed according to the historical rescue of Rosário do Sul. For the execution of the research was used the sample and collection of historical and current images in order to better illustrate the tourist point of analysis. In addition, we used bibliographical and documentary surveys that helped us during all the research for the accomplishment of the historical rescue of the municipality, this stage counted on the search in collections available in digital means and physical collection made available by schools and the city hall of the County. With the results the research pointed out that the municipality has an important tourist potential for the central region of the state, driven by the activity that it performs in the function of the Santa Maria River, which attracts people from the other municipalities of the region in function of White Sands Beach, as old buildings that denote the culture of different present migrations and with their trademarks registered in the cultural patrimony of the municipality.region in function of White Sands Beach, like old buildings that denote the culture of different present migrations and with their trademarks in the cultural patrimony of the city.
\end{abstract}

Keywords: Story; Attractions; Rosário do Sul; Tourism.

\title{
1. Introdução
}

A proposta principal deste trabalho visa compreender as relações culturais e turísticas presentes no município de Rosário do Sul (Figura 1), com a proposta de ressaltar os principais pontos turísticos e um breve resgate do histórico do município. Tal resgate histórico nos auxilia a compreender a importância de prédios e demais construções que contribuem para o turismo cultural do município.

Neste contexto Siqueira (2016) define o termo turismo como uma atividade econômica que está relacionada a viagens organizadas que, normalmente são realizadas a lazer. Porém as atividades turísticas podem ser de diferentes tipos (cultural, ecológico, econômico e afim).

O termo Turismo também pode ser considerado como um movimento de pessoas que abandonam temporariamente o lugar de residência permanente por qualquer motivo relacionado com o espírito, o corpo ou a profissão. (SCHWINCK, 1974, p. 24-28).

Já austríaco Hermann Von Schullern Zu Schattenhofen em 1911 foi um dos pioneiros na definição de turismo quando escrevia que "turismo é o conceito que compreende todos os processos, especialmente os econômicos, que se manifestam na chegada, na permanência e na saída do turista de um determinado município, país ou estado.", e só teria destaque aqui as definições posteriores à data de 1940.

Professores da Universidade de Berna, W. Hunziker e K. Krapf (1942) definiam o turismo como: "A soma dos fenômenos e de relações que surgem das viagens e das estâncias 
dos não residentes, desde que não estejam ligados a uma residência permanente nem a uma atividade remunerada".

Já a italiana Michele Troisi e o suíço Walter Hunziker diferem em seu conceito turístico, visto que ela defende tratar-se de viagens em sua essência, quando ele defende tratar-se de fenômenos e relações a partir da permanência do indivíduo em localidade diferente de sua residência e sem motivação por atividade lucrativa. Como um "Conjunto de viagens temporárias de pessoas motivadas por necessidades de repouso, de cura, espirituais ou intelectuais." (Michele Troisi, Itália 1942).

Em relação ao turismo histórico e cultural que é o que possui maior destaque no município podemos afirmar que uma vez que todas as atividades de turismo envolvem algum elemento de cultura, seja a visita a uma localidade ou a um evento cultural, ou simplesmente o desfrutar da "atmosfera" de um destino em um café de rua, há uma tentação em considerar todo turismo como "turismo cultural". Conforme a Organização Mundial do turismo (OMT) comentou recentemente, "a definição de cultura é quase tão vasta quanto a do próprio turismo. Junto com o patrimônio arquitetônico e das artes, alguns países incluem em sua definição, por exemplo, a gastronomia, o esporte, a educação, as peregrinações, o artesanato, a contação de estórias, e a vida na cidade" (2004).

O Turismo Cultural "compreende as atividades turísticas relacionadas à vivência do conjunto de elementos significativos do patrimônio histórico e cultural e dos eventos culturais, valorizando e promovendo os bens materiais e imateriais da cultura" (BRASIL, MTUR, 2006, p. 13) e a cultura está presente em toda relação entre o homem e a natureza e se refere àquilo que é produzido ou desenvolvido pelo homem em resposta às suas necessidades materiais, utilitárias e simbólicas, o que é apreendido socialmente. No turismo cultural, os bens do patrimônio - material e imaterial - são recursos usados para a formatação de produtos. $\mathrm{O}$ patrimônio material inclui bens pertencentes às categorias de arte arqueológica, etnográfica, ameríndia e popular, monumentos naturais, sítios e paisagens, bens de interesse histórico e obras de arte.

A partir das definições de turismo a proposta do trabalho foi à busca de pontos turísticos presentes no município de Rosário do Sul e destacando a sua importância para a contribuição histórica, cultural ou econômica dos pontos presentes no município. Neste contexto a pesquisa é norteada pelo objetivo geral de analisar a importância do turismo no município do Rosário do Sul para a região central do Rio Grande do Sul. E como objetivos específicos valorizar o turismo cultural de Rosário do Sul; ampliar o número de turistas para o 
desenvolvimento de Rosário do Sul; destacar histórico do município e relacionar com o turismo cultural local.

\section{Metodologia}

A metodologia do trabalho se baseou fundamentalmente na busca e leitura bibliográfica e de documentos que retratam a origem e o passado do município de Rosário do Sul em consulta a biblioteca pública municipal. Ademais, para o resgate histórico do município se observou a beleza arquitetônica da cidade que nos remete a compreender a história da ocupação e colonização de Rosário do Sul.

Para a observação dos pontos turísticos em destaque foi feita uma observação nos locais em que havia no momento ou houve em um passado recente uma aglomeração de pessoas que buscam conhecer, visitar ou até mesmo atividades de lazer dentro do município. Para complementar o resgate histórico foi procurado um acervo fotográfico que de imagens do passado no município para a compreensão da história. Além do acervo antigo foi feito um trabalho de campo visando capturar imagens de pontos turísticos em que não havia fotografias disponíveis para a inserção ou reinserção desses pontos turísticos do município.

\section{Resultados}

Os resultados foram organizados sistematicamente com a finalidade de cumprir os objetivos propostos pelo trabalho. A partir de então se inicia com a definição e conceituação de turismo cultural, apresentação da localização e breve histórico do município e por fim são apresentados e discutidos os principais pontos turísticos de Rosário do Sul.

\subsection{O Município de Rosário do Sul}

O município de Rosário do Sul teve sua origem a partir da Sesmaria do Passo do Rosário, em 1815. Sua primeira povoação era formada de barqueiros e canoeiros e já em 1856 contavam com casas ocupadas por famílias dedicadas ao comércio e agregados nativos. Possui duas das mais belas praias fluviais do estado: Areias Brancas e Praia do Rio Ibicuí.

Quanto a localização, Rosário do Sul está situado na fronteira oeste do estado do Rio Grande do Sul, limitando com os seguintes municípios: ao norte Cacequi, ao sul Sant'Ana do Livramento, a leste São Gabriel, Lavras do Sul e Dom Pedrito e a oeste Alegrete e Quaraí. O município que está no corredor do Mercosul com ligação através da BR 290, tem acesso facilitado à todas as regiões do estado (figura 1). 


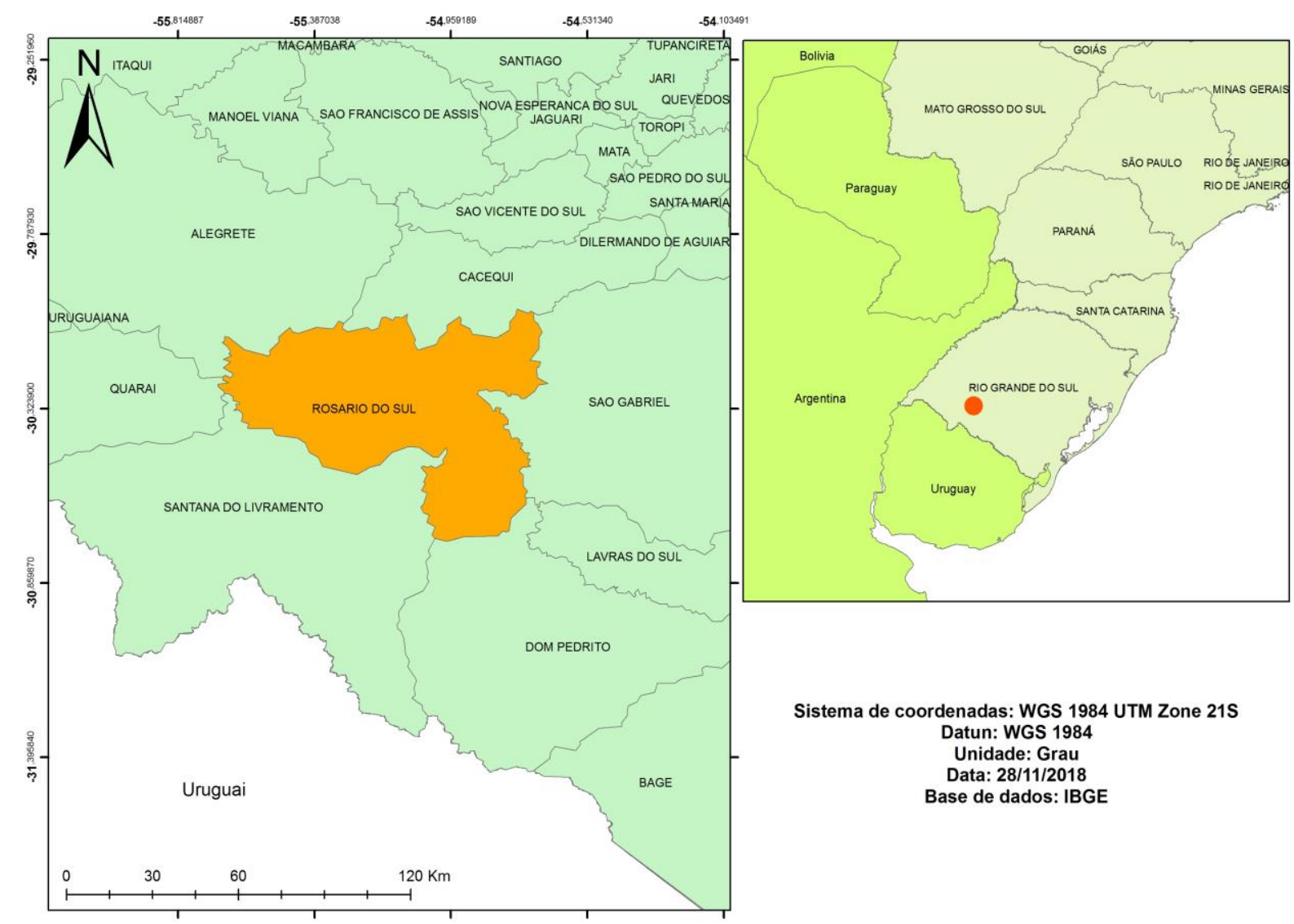

Figura 1 - Mapa de Localização do Município de Rosário do Sul.

Fonte e Elaboração: Janderlei Velasque Dal Osto

Rosário do Sul é conhecida por sua diversidade de Pontos Turísticos, sejam eles naturais, religiosos ou históricos, destacam-se entre eles, a Praia das Areias Brancas, de água doce e considerada a mais bela praia fluvial do Estado, recebeu este nome pelos seus $3 \mathrm{~km}$ de areias finas e brancas. Ponto arborizado com infraestrutura completa de camping, local para caminhadas, restaurantes e bares, também é palco de concursos e shows. Possui uma extensa área de lazer que turistas e munícipes desfrutam durante a temporada de verão.

Outro ponto turístico natural é a Serra do Caverá, lindo local, composto por uma cadeia de picos quebrados, encravados entre as coxilhas pampeanas por cerros limpos e moderadamente ondulados. Foi palco de batalhas e revoluções, e ainda protege Rosário do Sul de fortes ventos e tempestades.

Inaugurada em 1969, a Ponte Marechal José de Abreu fica sobre o Rio Santa Maria, ela sai do município, na direção Leste. Considerada a maior ponte de concreto armado da Metade Sul do Estado, possui 1.772 metros de extensão, sendo a ligação entre os municípios das regiões Oeste e Leste do Rio Grande do Sul através da BR-290, bem como passagem de turistas da Argentina e Uruguai. 
Como turismo religioso, destaca-se o Monumento a Nossa $\mathrm{Sr}^{\mathrm{a}}$. De Fátima, localizado na Praça do Estudante, é um monumento de alvenaria em forma cilíndrica, medindo 26m, encimado por uma imagem de Nossa Senhora de Fátima, réplica da existente na cidade de Fátima em Portugal, sendo ainda, um dos mais altos monumentos religiosos em homenagem a esta Santa da América do Sul.

No turismo histórico, ganha destaque a célebre Batalha do Passo do Rosário, também conhecida como Batalha do Ituzaingó, entre os exércitos Brasileiro e Argentino. Batalha esta sem vencidos nem vencedores, que originou a República Oriental do Uruguai.

\subsection{Pontos Turísticos de Rosário do Sul}

Os pontos turísticos foram listados considerando a sua importância dentro da influência no município. Cada ponto possui um breve histórico e descrição do contexto em que foi inserido.

O Theatro Municipal João Pessoa (figura 2) é o primeiro ponto em destaque, este foi construído em 1912, durante a administração do Coronel Sabino de Araújo e a restauração começou em 24/10/2006 no Governo do Sr. Prefeito Ney da Silva Padilha estando ainda em andamento. Não havia capacidade de lotação disponível da parte superior tem uma estrutura arquitetônica que nos remete ao século XX. Atualmente, o Theatro conta com espetáculos locais principalmente promovidos pelas escolas locais. Entretanto, ainda é ponto de encontro frequente e uma referência cultural para shows e espetáculos do público em geral que, periodicamente, se apresentam no local.

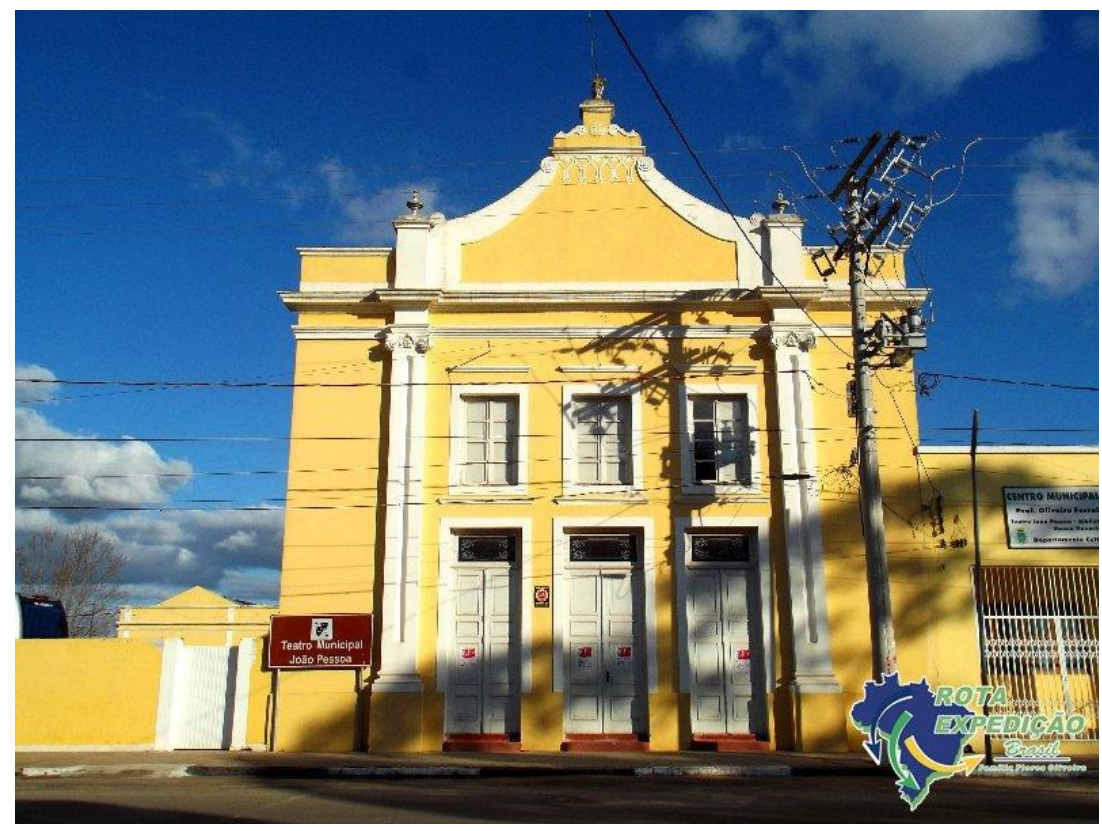

Figura - Theatro Municipal João Pessoa

Fonte: http://www.rotaexpedicao.com.br/home/rosario-do-sul-rs/ 
O segundo ponto em destaque trata-se da Praia das Areias Brancas (figura 3), está localizada no Rio Santa Maria, um rio de água doce com $3 \mathrm{~km}$ de extensão de areias finas e brancas que deram nome ao local "Areias Brancas". Local arborizado cortado por três vias largas calçadas que cobrem praticamente toda sua extensão, possui infraestrutura turística completa com camping, bares, restaurantes, sanitários, área de lazer ideal para caminhadas e palco para realização de concursos e shows.

Os eventos na praia ocorrem sazonalmente no período de estações com temperaturas mais elevadas (Primavera e Verão) nesse período, portanto, a praia trata-se do principal ponto turístico da cidade. Devido ao acesso bem mais acessível em relação ao litoral do estado do Rio Grande do Sul, a praia atrai os turistas de várias regiões, mas principalmente aqueles das regiões Oeste e Central do estado. A Praia das Areias Brancas possui um papel importante para economia local do município, muitos estabelecimentos inclusive só abrem no período em que há maior movimentação na praia.

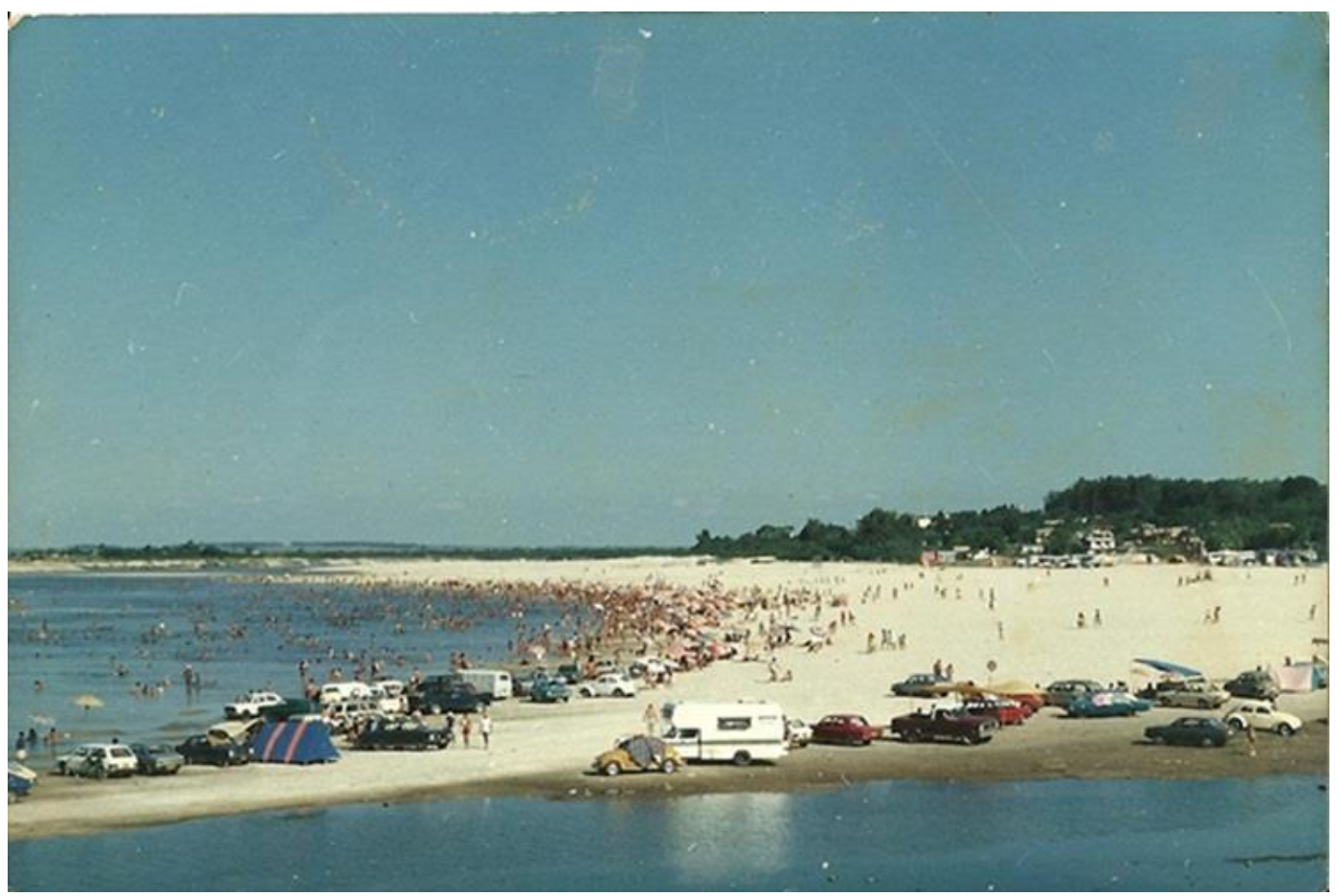

Figura 3 - Praia das Areias Brancas

Fonte: http://rosariodosulemfotos.blogspot.com/2012/01/praia-das-areias-brancas-na-decada-de.html

O terceiro ponto é o Parque de Exposições Ananias Vasconcellos, este possui um gramado e árvores, estandes para animais, local para acampar, sanitários, mangueiras, restaurantes, espaços comerciais para empresas, centro de eventos. É um importante ponto de encontro para pessoas que principalmente buscam lazer, além disso, conta com eventos locais como apresentações e shows (principalmente de músicas nativistas) com maior aglomeração de eventos e exposições realizadas nos fins de semana. 
Já o quarto ponto é a Praça Central Borges de Medeiros (figura 4) essa praça é a principal da cidade, possui área de $400 \mathrm{~m}^{2}$, no centro da cidade, arborizado, com playground, monumentos, banheiros masculino e feminino e rodeado por carros de lanches, farmácia, Prefeitura, Teatro e Biblioteca Municipal, Igrejas, Clube Social, Escola, Bancos e prédios históricos, é um dos lugares de lazer que possui grande número de pessoas diariamente. Além disso a praça nos remete uma volta no passado, pois possui monumentos que retratam a história do Brasil, Rio Grande do Sul e do próprio município, dentre os monumentos destacase: o Monumento em homenagem a Getúlio Vargas: Monumento em forma de obelisco com pedestal em alvenaria encimado pelo busto de Getúlio Vargas em bronze e ao pé a frase "À sanha de meus inimigos, deixo o legado de minha morte. Levo o pesar de não ter podido fazer pelos humildes, tudo aquilo que desejava". Ao lado do monumento principal, tem um pequeno pedestal em alvenaria com a Carta Testamento em bronze transcrita na íntegra; Monumento em homenagem a Honório Lemes: Monumento de alvenaria revestido com pedras de granito com placa em bronze com a face do caudilho, inscrições com obituário, homenageando o Cinquentenário da Revolução de 1923 e citação da famosa frase: "Quero leis que governem homens e não homens que governem leis"; Monumento em homenegem a Padre Ângelo Bartelle: Monumento em alvenaria com pedestal de pedra encimado pelo busto do padre, em gratidão ao seu jubileu sacerdotal pelos benefícios prestados durante 42 anos de sacerdócio e magistério ao município e oferecido por ex-alunos e população rosarienses.

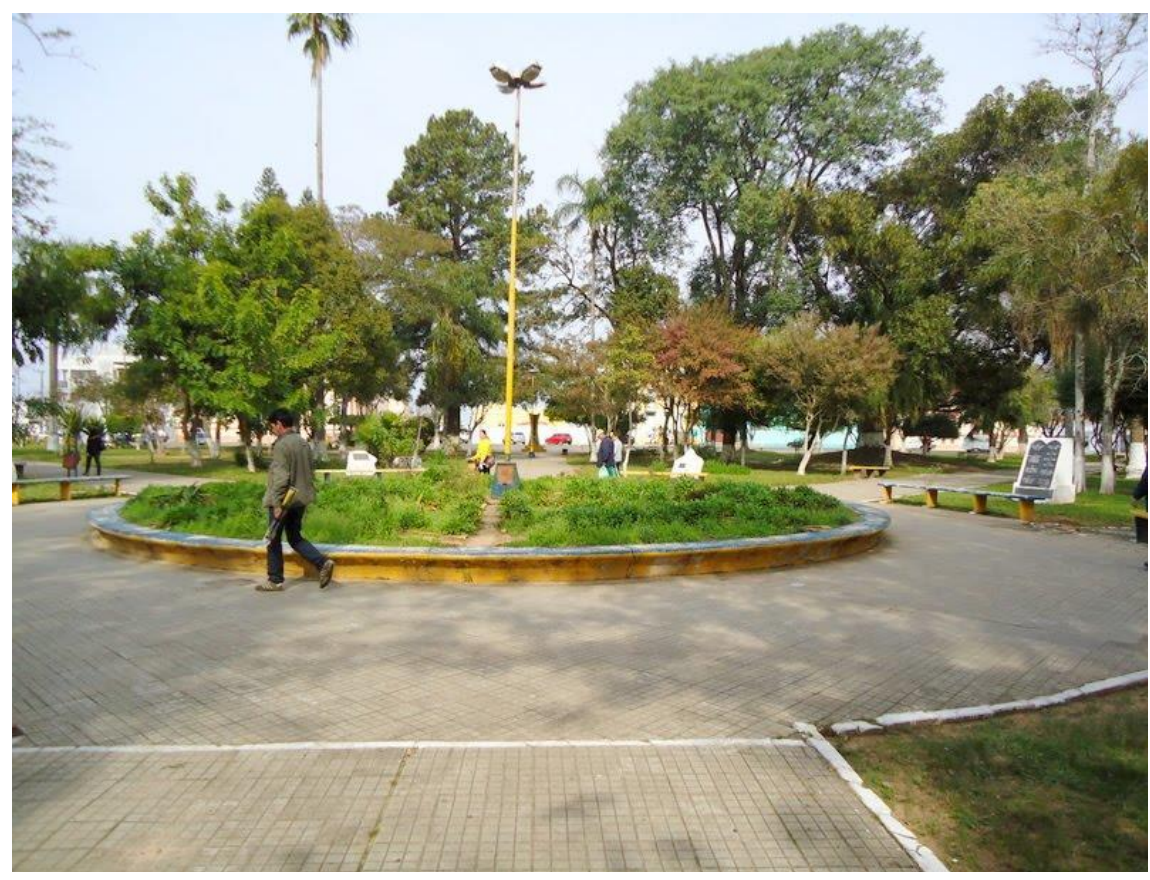

Figura 4 - Praça Borges de Medeiros

Fonte: http://rosariodosulemfotos.blogspot.com/2011/10/praca-borges-de-medeiros-canteiro.html 
O quinto ponto de destaque é o Museu Particular Cultural situado no centro do município o museu possui um acervo de indumentária, uniformes, armaria, objetos de uso pessoal de guerras (Revolução Farroupilha, Era Jesuíta, etc.), automóveis antigos, numismática, filatelia e fósseis que retratam e resgatam a história do município com antiguidades únicas. As peças do museu são de exposição permanente e o acervo de materiais conta 5.014 peças.

Ademais há o Museu Municipal General Honório Lemes em que consta um acervo de objetos de uso pessoal do general Honório Lemes, objetos da batalha do Poço do Rosado, busto do marechal José de Abreu, instrumentos musicais, equipamentos de reprodução sonora, jornais e o Monumento em homenagem a Nossa Sra de Fátima que se trata de um monumento de alvenaria em forma cilíndrica medindo 25 metros encimado por uma imagem de Nossa $\mathrm{Sr}^{\mathrm{a}}$ de Fátima, réplica da que existe em Fátima, Portugal, em tamanho natural possui uma base que é uma capela de alvenaria que possui em seu interior um altar com uma imagem menor de Nossa Sra de Fátima. Em cima da capela lê-se a inscrição: "Sra de Fátima, Salvai o Mundo".

Destaque também para o Mausoléu de Honório Lemes (Monumento Fúnebre) que é uma Capela mortuária em alvenaria, de cor verde, com porta e janela brancas, pé direito de 4 metros de altura, encimando pela inscrição $\mathrm{H}$. lemes e ao lado da porta uma placa branca com a célebre frase: "Quero leis que governem homens e não homens que governem leis". Honório Lemes. Homenagem dos tradicionalistas de Livramento e Rosário do Sul por ocasião da cavalgada realizada em 30/09/91.

Com o enfoque natural há a Área de Proteção Ambiental Ibirapuitã localizada na região sudoeste do Rio Grande do Sul, abrangendo os municípios de de Alegrete (15,22\%), Quaraí (12,22\%), Santana do Livramento (56,81\%) e Rosário do Sul (15,75\%) num perímetro de $260 \mathrm{~km}$. O clima da região é subtropical, com chuvas bem distribuídas e estações bem definidas. A temperatura média anual é de $18,6^{\circ} \mathrm{C}$. Ela foi criada com o objetivo de fomentar o turismo ecológico, a educação ambiental e a pesquisa científica, preservar a cultura e as tradições do gaúcho da fronteira, bem como proteger espécies ameaçadas de extinção em nível regional.

E por fim a Biblioteca Pública Municipal Dr. Werneldo Hörbe situada junto com o museu este acervo possui cerca de 15.500 livros que retratam diversos temas e história do Rio Grande do Sul e município. E é um importante ponto de encontro cultural principalmente pelas escolas locais do município. 


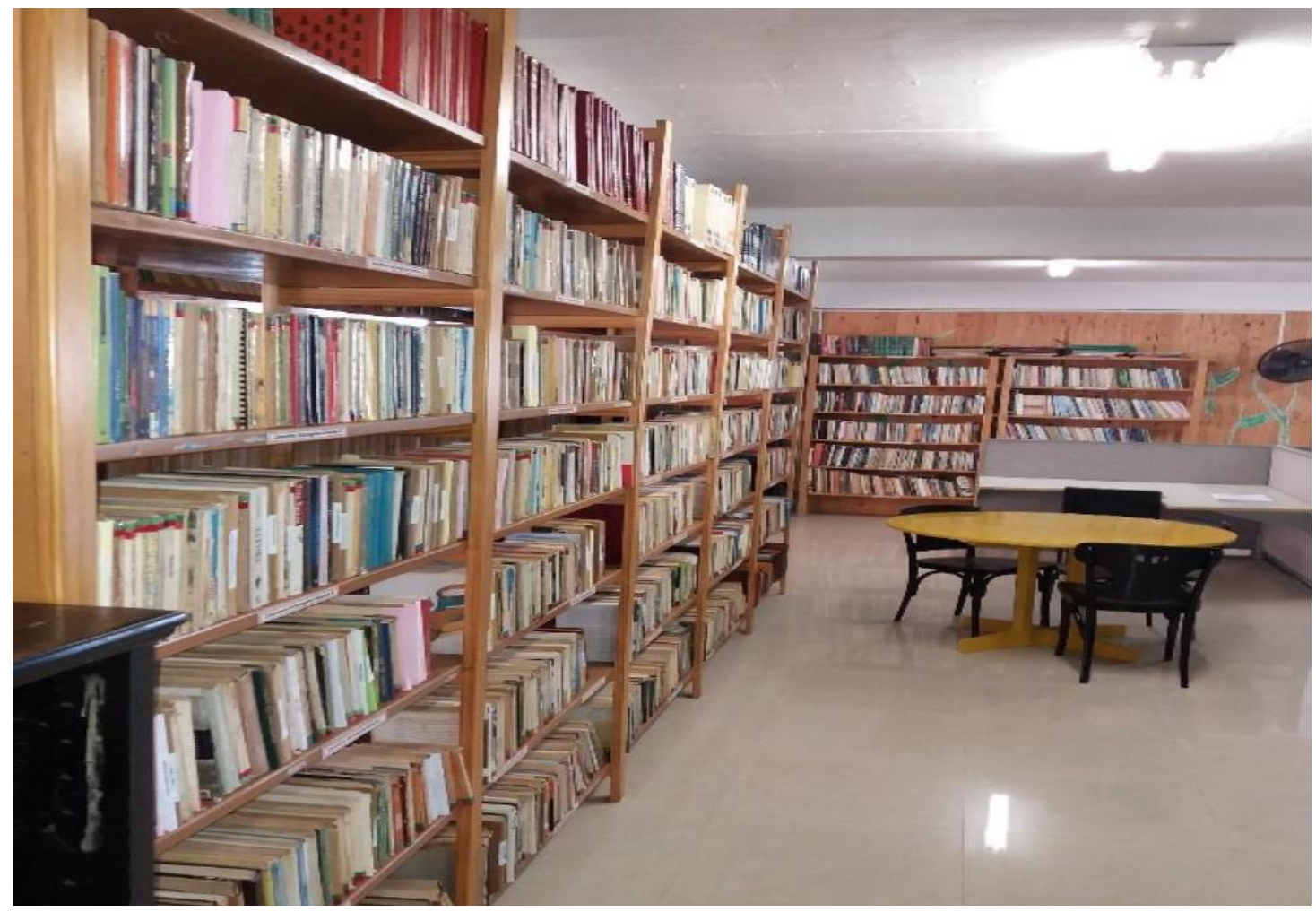

Figura 5 - Biblioteca Pública Municipal Dr. Werneldo Hörbe:

Fonte: os autores

\section{Considerações Finais}

É possível concluir que o município de Rosário do Sul possui um potencial turístico importante para região central do estado do Rio Grande do Sul que é impulsionado principalmente pela praia das areias brancas. Possui um papel fundamental e atrai gente de praticamente todos os municípios do centro e da região oeste do estado. Há um grande fluxo em direção ao município (praia), principalmente nos meses de janeiro, fevereiro e dezembro.

No que diz respeito ao turismo cultural de Rosário do Sul, há vários pontos e obras arquitetônicas que retratam a memória e cultura dos povos que habitaram a região. Muitos deles possuem atualmente condições precárias de infraestrutura e muitas vezes caem no esquecimento ou desconhecimento por parte da população da local, que em partes não possuem o conhecimento histórico de monumentos e edificações presentes na área central do município.

Ademais, é preciso destacar as limitações da pesquisa devido a falta de material e referências que dissertem sobre o município de Rosário do Sul, há um distanciamento da população local pela historia e cultura do município. Portanto, Rosário não se desenvolve em muitos aspectos porque boa parte da população local desconhece ou sabe pouco sobre a origem e importância dos acervos e edificações presentes no território. 
Por fim, a pesquisa conclui uma fase inicial de destacar e dissertar ainda que de forma sucinta sobre os pontos turísticos da cidade. Porém, é possível ampliar e levar esses pontos para que os moradores locais reconheçam e saibam da importância de manter e melhorar o rico potencial turístico que o município possui e assim, auxiliando no desenvolvimento do município.

\section{Referências}

AMSTERDAM: INTERNATIONAL STUDENT TRAVEL CONFEDERATION (ISTC). Also available online www.aboutistc.org.

ANDREAZZA, R. Hospital de Caridade Nossa Senhora Auxiliadora, 2005

FENLEY, L. (2003) Musical Tourism: A Harmonious Experience. http://www.fas.harvard.edu/ drclas/publications/revista/Tourism/fenley.html

MCKERCHER, BOB, HO, PAMELA S. Y. and Hilary du Cros (2004) Attributes of Popular

Cultural Attractions in Hong Kong. Annals of Tourism Research, 31, 393-407.

ORGANIZACIÓN MUNDIAL DEL TURISMO (OMT), (1996): Implications of the UN/WTO TourismDefinitions for the U. S. Tourism Statistical System, (1994): Recomendaciones sobre Estadísticas deTurismo, Madrid.

ORGANIZACION MUNDIAL DEL TURISMO (OMT), (1995): Concepts, Definitions and Clasificationsfor Tourism Statistics: a Technical Manual, Madrid

RICHARDS, G. (1996) Cultural Tourism in Europe. CAB International, Wallingford, 352pp.

RICHARDS, G. (2001, ed.) Cultural Attractions and European Tourism. CAB International, Wallingford. 259pp.

RICHARDS, G. (2009) Turismo cultural: Padres e implicaes. In de Camargo, P. and da Cruz, G. (eds) Turismo Cultural: Estratgias, sustentabilidade e tendncias. UESC: Bahia, pp. $25-48$.

RICHARDS, G. e RAYMOND, C. (2000) Creative Tourism. ATLAS News, no. 23, 16-20.

RICHARDS, G. e WILSON, J. (2003) New Horizons in Independent Youth and Student Travel.

RICHARDS, G. e WILSON, J. (2004) The Global Nomad: Theory and practice in Backpacker travel. Clevedon: Channel View Publications.

ROSÁRIO DO SUL, Rosário do Sul Centenário, 1976. 
SOUZA, M, R, M. Rosário do Sul Através do Tempo. Apontamentos de Mario Ortiz de Vasconcellos, 2005.

SOUZA, M. GOTTARDI, M. Paróquia Nossa Senhora do Rosário, 2004.

SOUZA, M. Parlamento de Rosário do Sul, 2007.

SILVA, MARIA DA GLÓRIA LANCI, (2004) Cidades turísticas: Identidades a cenários de lazer. São Paulo: Aleph.

TIA (2003) The Historic/Cultural Traveler. Washington: TIA.

WTO (2004) Tourism Market Trends, Madrid:World Tourism Organisation 